\title{
Basal and Spasmolytic Effects of a Hydroethanolic Leaf Extract of Melissa officinalis L. on Intestinal Motility: An Ex Vivo Study
}

\author{
Philippe Aubert, ${ }^{1}$ Isabelle Guinobert, ${ }^{2,3}$ Claude Blondeau, ${ }^{2,3}$ Valérie Bardot, ${ }^{2,3}$ \\ Isabelle Ripoche, ${ }^{4}$ Pierre Chalard, ${ }^{4}$ and Michel Neunlist ${ }^{1}$ \\ ${ }^{1}$ Bretagne Loire University, Nantes University, INSERM 1235, IMAD, \\ The Enteric Nervous System in Gut and Brain Disorders, Nantes, France. \\ ${ }^{2}$ PiLeJe Group, Paris, France. \\ ${ }^{3}$ Naturopôle, Saint-Bonnet de Rochefort, France. \\ ${ }^{4}$ Clermont Auvergne University, CNRS, SIGMA Clermont, Clermont-Ferrand Chemistry Institute, Clermont Ferrand, France.
}

\begin{abstract}
Melissa officinalis L. (lemon balm) has been used for decades with symptomatic benefits in patients with digestive disorders. However, very little is known on the effects of M. officinalis on the gastrointestinal (GI) tract. In this study, the basal and spasmolytic properties of a hydroethanolic leaf extract (HLE) of M. officinalis were assessed ex vivo on different segments of the GI tract of mice after phytochemical characterization of the extract. M. officinalis HLE had site- and dose-dependent effects on the contractile activity of the GI tract, the motility response being impacted in the jejunum and ileum but not in the antrum and colon. The observed effects could be caused by the phenolic compounds (mainly rosmarinic acid) detected in the extract.
\end{abstract}

KEYWORDS: • hydroethanolic extract $\bullet$ intestine $\bullet$ lemon balm $\bullet$ rosmarinic acid

\section{INTRODUCTION}

$M$ ELISSA OFFICINALIS L., also known as lemon balm, is a medicinal plant that has long been used in traditional medicine for digestive comfort and its impact upon mood and cognitive performance. ${ }^{1-3}$ As for gastrointestinal (GI) function, the European Medicines Agency acknowledged M. officinalis folium as a traditional herbal medicinal product for the symptomatic treatment of mild GI complaints including bloating and flatulence, ${ }^{4}$ and the European Scientific Cooperative On Phytotherapy, for the symptomatic treatment of digestive disorders such as minor spasms. ${ }^{5}$

Although M. officinalis has been used for decades with symptomatic benefits in patients with digestive disorders, to date, little is known on the effects of M. officinalis on the GI

Manuscript received 1 October 2018. Revision accepted 26 February 2019.

Address correspondence to: Michel Neunlist, PhD, Bretagne Loire University, Nantes University, INSERM 1235, IMAD, The Enteric Nervous System in Gut and Brain Disorders, 1 rue Gaston Veil, Nantes 44035, France, E-mail: michel.neunlist@univ-nantes.fr

(C) Philippe Aubert et al. 2019; Published by Mary Ann Liebert, Inc. This Open Access article is distributed under the terms of the Creative Commons License (http:// creativecommons.org/licenses/by/4.0), which permits unrestricted use, distribution, and reproduction in any medium, provided the original work is properly cited. tract. The pathophysiological concepts concerning functional disorders of the GI tract include disturbances in motility and acid production as underlying mechanisms. Results of the few studies that have been performed to characterize the effects of $M$. officinalis, mainly on motility, are scarce and often contradictory. Most of the studies available were performed with $M$. officinalis folium extract that is a constituent of a marketed fixed combination of nine herbal extracts. ${ }^{6-10}$ The observations made in these studies were dependent on the gut part tested and were in part species dependent. For instance, Forster et al. did not show spasmolytic activity of $M$. officinalis in the guinea pig ileum while Heinle et al. observed a reduction in histamineinduced contractile response. ${ }^{6,7}$ Furthermore, under basal conditions, Schemann et al. reported increased motility in proximal and distal stomach while Sibaev et al. observed lemon balm leaf had no effects in basic electrophysiological properties of smooth muscle cells in the ileum. ${ }^{8,9}$ Altogether, no comprehensive studies on the effects of $M$. officinalis hydroethanolic leaf extracts (HLEs) upon basal contractile activity and spasmolytic activity in various gut segments have been performed. Therefore, the basal and spasmolytic properties of HLE of M. officinalis were assessed ex vivo on different segments of the GI tract of mice after phytochemical characterization of the extract. 


\section{MATERIALS AND METHODS}

M. officinalis leaves were collected in Aubiat (France) in June 2015 and identified by Gilles Thébault from the herbarium of Museum d'Histoire Naturelle Henri-Lecoq (Clermont-Ferrand, France) where a voucher specimen was deposited (CLF106452). This herbarium is referenced with the international association for plant taxonomy whose head office is in the New York botanical garden.

\section{Preparation of M. officinalis $H L E$}

M. officinalis HLE was produced by PiLeJe Industrie (France) according to the patented process WO2001056 584A1. The procedure was standardized and the extract quality was controlled by thin layer chromatography, and by high-performance liquid chromatography (HPLC) for determination of rosmarinic acid content as described in the European Pharmacopeia monograph (ref 01/2011:1447). $M$. officinalis fresh frozen leaves were extracted with $20 \%$ to $70 \%(\mathrm{v} / \mathrm{v})$ ethanolic leaching. The extract was concentrated under reduced pressure to evaporate ethanol and then ethanol concentration was adjusted to $30 \%$. M. officinalis HLE in ethanol was used in ex vivo experiments. The specific batch used in the study (no. C-14J297) contained $8.6 \%$ of dry material that held $5.3 \%$ of rosmarinic acid. The yield of extraction as a percentage weight of the dry matter of starting fresh plant material was $24 \%$. After addition of glycerol, the M. officinalis HLE is a rosmarinic acid standardized extract of M. officinalis (EPS Mélisse; PiLeJe Laboratoire, France).

\section{Phytochemical analysis of M. officinalis $H L E$}

Chemical composition of $M$. officinalis HLE was further analyzed using ultra-HPLC (UHPLC). Chromatographic analyses by UHPLC were performed on an Ultimate 3000 RSLC UHPLC system (Thermo Fisher Scientific, Inc., MA, USA) coupled to a quaternary rapid separation pump (Ultimate autosampler) and a rapid separation diode array detector. Compounds were separated on a Uptisphere Strategy C18 column $(250 \times 4.6 \mathrm{~mm}, 5 \mu \mathrm{m}$; Interchim), which was controlled at $30^{\circ} \mathrm{C}$. The mobile phase was a mixture of $0.1 \%$ $(\mathrm{v} / \mathrm{v})$ formic acid in water (phase A) and $0.1 \%(\mathrm{v} / \mathrm{v})$ formic acid in acetonitrile (phase $\mathrm{B}$ ). The gradient of phase A was $100 \%$ (0-39 min), 0\% (40-49 min), 100\% (50-60 min), and then was held at $100 \%$. The flow rate was $0.8 \mathrm{~mL} / \mathrm{min}$, and the injection volume was $5 \mu \mathrm{L}$. The UHPLC system was connected to an Orbitrap (Thermo Fisher Scientific, Inc.) mass spectrometer, operated in negative electrospray ionization mode. Source operating conditions were as follows: $3 \mathrm{kV}$ spray voltage; $320^{\circ} \mathrm{C}$ heated capillary temperature; $400^{\circ} \mathrm{C}$ auxiliary gas temperature; sheath, sweep, and auxiliary gas (nitrogen) flow rate of 50, 10 and 2 arbitrary units, respectively; and collision cell voltage between 10 and $50 \mathrm{eV}$. Full scan data were obtained at a resolution of 70,000, whereas tandem mass spectrometry $\left(\mathrm{MS}^{2}\right)$ data were obtained at a resolution of 17,500. Data were processed using Xcalibur software (Thermo Fisher Scientific, Inc.).
Compounds detected were characterized according to their retention times, mass spectral data, and comparison with authentic standards when available or with data found in the literature. ${ }^{3}$

\section{Effects of M. officinalis HLE on GI motility}

Male C57BL/6J Rj mice aged 8 weeks $(n=40$; Janvier Laboratory, Le Genest-Saint-Isle, France) were maintained on a $12 \mathrm{~h}$ light $-12 \mathrm{~h}$ dark cycle $\left(22^{\circ} \mathrm{C}\right)$ and had free access to food and water. After 1-week adaptation period, mice were killed by cervical dislocation. Whole stomach and intestine of each mouse were quickly excised and placed in an icecold Hank's buffer saline solution. Circular muscle strips (10 $\mathrm{mm}$ in length and $0.2 \mathrm{~mm}$ in width) were cut from the distal antrum region and longitudinal strips from jejunum, ileum, and proximal colon. Muscle preparations were suspended vertically in an organ bath filled with Krebs solution $\left(\mathrm{NaCl}, 117 \mathrm{mM} ; \mathrm{KCl}, 4.7 \mathrm{mM} ; \mathrm{MgCl}_{2}, 1.2 \mathrm{mM} ; \mathrm{NaH}_{2} \mathrm{PO}_{4}\right.$, $1.2 \mathrm{mM} ; \mathrm{NaHCO}_{3}, 25 \mathrm{mM} ; \mathrm{CaCl}_{2}, 2.5 \mathrm{mM}$; and glucose, $11 \mathrm{mM}$ ) warmed at $37^{\circ} \mathrm{C}$ and gassed with $95 \% \mathrm{O}_{2}+5 \% \mathrm{CO}_{2}$. Muscle strips were stretched with a tension of 4-6 mN. Isometric contractions were continuously recorded by using isometric force transducers (No. TRI202PAD; Panlab, Cornellã, Spain) coupled to a computer equipped with the PowerLab 8/30 System and the Labchart data analysis software (AD Instruments, Spechbach, Germany).

Basal effects were assessed after a 30-min equilibration period. Muscle strips $(n=10$ per condition) were treated with increasing concentrations of $M$. officinalis $\operatorname{HLE}(1,5$, 10,25 , and $50 \mathrm{mg} / \mathrm{mL}$ corresponding, respectively, to 0.077 , $0.39,0.77,1.9$, and $3.87 \mathrm{mg} / \mathrm{mL}$ of dry material and 0.004 , $0.02,0.04,0.1$, and $0.2 \mathrm{mg} / \mathrm{mL}$ of rosmarinic acid) or ethanol (at corresponding concentrations, i.e., 0.3, 1.5, 3, 7.5, and $15 \mathrm{mg} / \mathrm{mL}$ ). Muscle strips were then washed in Krebs solution for $15 \mathrm{~min}$ and treated with nifedipine $10 \mu \mathrm{M}$ (myorelaxant positive control) after a 15 -min equilibration period. The protocol for the assessment of spasmolytic effects was identical except steady-state muscle strips were precontracted with the muscarinergic agonist bethanechol $(100 \mu \mathrm{M})$ before treatment with $M$. officinalis HLE or ethanol then, after washing with Krebs solution, treated with bethanechol and nifedipine for control.

Frequency of spontaneous phasic contractions was evaluated for $2 \mathrm{~min}$ and contractile activity was assessed by measuring the area under the curve (AUC) for $2 \mathrm{~min}$. These two parameters were assessed before and after addition of $M$. officinalis HLE or ethanol. Values are expressed as mean \pm standard error of the mean. Graphs and statistical analysis were performed using GraphPad Prism 5.00 (GraphPad Software, Inc., La Jolla, CA, USA). Friedman's test followed by Dunn's test was used to analyze the dose-response effect of M. officinalis HLE or ethanol. Treatment effects were compared using two-way analysis of variance (ANOVA) for repeated measures followed by Bonferroni post hoc test. Nifedipine effects were analyzed with Wilcoxon test. Results were considered statistically significant when $P<.05$. All values were normalized to tissue weight and expressed in 
percentage compared with initial value before treatment with M. officinalis HLE or ethanol.

\section{RESULTS}

\section{Composition of M. officinalis $H L E$}

M. officinalis HLE phytochemical profile was determined by liquid chromatography/mass spectrometry (LC/MS) and LC/MS ${ }^{2}$ analyses in the negative ionization mode. Major compound was rosmarinic acid (Fig. 1; Table 1, signal 14, $\mathrm{M}-\mathrm{H}^{-}:$359.0767). Several caffeic and rosmarinic acid derivatives such as danshensu (Fig. 1; Table 1, signal 6), 3'-O-( $8^{\prime \prime}-$ Z-caffeoyl)-rosmarinic acid (signal 15), ethyl caffeate (signal 16 ), and flavonoids such as luteolin $3^{\prime}$-O- $\beta$-D-glucuronide (signal 13) were also identified.

\section{Effects on GI tract motility}

Antrum. Both in basal and precontracted conditions, effects of $M$. officinalis HLE on antrum were not significantly different from those of ethanol (vehicle; Table 2).

In basal conditions, both $M$. officinalis HLE and ethanol induced a significant decrease in the frequency of antrum contractions at 25 and $50 \mathrm{mg} / \mathrm{mL}$ (for HLE, doses correspond, respectively, to 1.9 and $3.87 \mathrm{mg} / \mathrm{mL}$ of dry material; Friedman's test: $P=.0003$ [ $n=9$ ] for $M$. officinalis HLE, $P<.0001$ $[n=7]$ for ethanol; Dunn's test: $-94.6 \% \pm 5.4 \%$ and $-100 \% \pm$ $0.0 \%$, respectively, $P<.05$ vs. control [i.e. previous treatment] for both $M$. officinalis HLE and ethanol; data not shown) without any significant difference between two treatments (two-way ANOVA, $P=.95 ;$ M. officinalis $\operatorname{HLE} n=9$; ethanol $n=7)$. There was no significant effect of M. officinalis HLE on the contractile activity of antrum (AUC), whereas ethanol significantly decreased AUC at corresponding concentrations of 5 and $10 \mathrm{mg} / \mathrm{mL}$ (Friedman's test: $P=.0005$ [ $n=7]$; Dunn's test: $P<.05$ vs. control). However, the difference between the two treatments was not significant.

In the precontracted antrum, there was no significant change in frequency of phasic contractions with $M$. officinalis HLE whatever the concentration (Friedman's test: $P=.12[n=10])$. Although ethanol induced a significant decrease in that frequency at corresponding concentration of $50 \mathrm{mg} / \mathrm{mL}$ (Friedman's test: $P=.0002[n=10]$; Dunn's test: $P<.05$ vs. control $[n=10])$, the difference between two treatments was not significant (two-way ANOVA, $P=.83$; M. officinalis HLE $n=10$; ethanol $n=10$ ). Similar observations were made for the contractile activity (AUC): no effect of $M$. officinalis, significant effect of ethanol at corresponding concentrations of 25 and $50 \mathrm{mg} / \mathrm{mL}$, and no difference between the two treatments.

Nifedipine significantly inhibited phasic contractions and AUCs in all conditions (for antrum and all GI parts).

Jejunum. In basal conditions (Table 2, Figs. 2 and 3A), M. officinalis HLE significantly decreased the frequency of spontaneous phasic contractions of jejunum at 25 and $50 \mathrm{mg} / \mathrm{mL}$ (corresponding, respectively, to 1.9 and $3.87 \mathrm{mg} / \mathrm{mL}$ of dry material; Friedman's test: $P<.0001[n=9]$; Dunn's test: $-14.2 \% \pm 3.1 \%$ and $-48.5 \% \pm 11.6 \%$, respectively, $P<.05$ vs. control [i.e. previous treatment]), whereas no decrease was observed with ethanol (Friedman's test: $P=.23[n=10])$. The difference between $M$. officinalis and ethanol was statistically significant at 25 and $50 \mathrm{mg} / \mathrm{mL}$ (two-way ANOVA, $P=.0015$; Bonferroni test, $P<.05$; $M$. officinalis HLE $n=9$; ethanol $n=10$ ). With regard to the contractile activity, a significant AUC reduction was observed with $M$. officinalis HLE at 10,25 , and $50 \mathrm{mg} / \mathrm{mL}$ (corresponding, respectively, to $0.77,1.9$, and $3.87 \mathrm{mg} / \mathrm{mL}$ of dry material; Friedman's test: $P<.0001[n=9]$; Dunn's test: $-58.0 \% \pm 11.8 \%,-82.6 \% \pm 15.1 \%$, and $-90.1 \% \pm 14.0 \%$, respectively, $P<.05$ vs. control). The difference between the two treatments was statistically significant at 10,25 , and $50 \mathrm{mg} / \mathrm{mL}$ (two-way ANOVA, $P=.011$; Bonferroni test, $P<.05 ; M$. officinalis HLE $n=9$; ethanol $n=10$ ).

Similarly, in precontracted conditions (Table 2, Figs. 2 and 3B), M. officinalis HLE significantly decreased frequency of spontaneous phasic contractions of jejunum at 25 and $50 \mathrm{mg} / \mathrm{mL}$ (corresponding, respectively, to 1.9 and $3.87 \mathrm{mg} / \mathrm{mL}$ of dry material; Friedman's test: $P<.0001$ $[n=10]$; Dunn's test: $-13.5 \% \pm 3.4 \%$ and $-59.3 \% \pm 13.9 \%$, respectively, $P<.05$ vs. control [i.e., previous treatment]), whereas no decrease was reported with ethanol (Friedman's test: $P=.34[n=10])$. The difference between two treatments was statistically significant at $50 \mathrm{mg} / \mathrm{mL}$ (two-way ANOVA, $P=.011$; Bonferroni test, $P<.05 ; M$. officinalis HLE $n=10$; ethanol $n=10$ ). As for the contractile activity, both $M$. officinalis HLE and ethanol induced a significant decrease in AUC at 10,25 , and $50 \mathrm{mg} / \mathrm{mL}$ (for HLE, doses correspond, respectively, to $0.77,1.9$, and $3.87 \mathrm{mg} / \mathrm{mL}$ of dry material; Friedman's test: $P<.0001[n=10]$, Dunn's test: $P<.05$ for both $M$. officinalis HLE and ethanol; $-48.4 \% \pm 7.7 \%,-86.3 \% \pm 10.1 \%$, and $-106.2 \% \pm 11.9 \%$, respectively, for $M$. officinalis HLE). AUC decrease observed with $M$. officinalis HLE was significantly greater than that with ethanol, at corresponding concentrations of 10,25, and $50 \mathrm{mg} / \mathrm{mL}$ (two-way ANOVA, $P=.0021$; Bonferroni test, $P<.05 ;$ M. officinalis HLE $n=10$; ethanol $n=10$ ).

Ileum. In basal conditions (Table 2 and Fig. 4), M. officinalis HLE significantly decreased the frequency of spontaneous phasic contractions of ileum at $50 \mathrm{mg} / \mathrm{mL}$ (corresponding to $3.87 \mathrm{mg} / \mathrm{mL}$ of dry material; Friedman's test: $P<.0001[n=10]$; Dunn's test: $-65.6 \% \pm 14.1 \% P<.05$ vs. control [i.e., before treatment]). In contrast, there was no significant decrease with ethanol (Friedman's test: $P=.057$ $[n=9])$. The difference between M. officinalis HLE and ethanol was statistically significant at 25 and $50 \mathrm{mg} / \mathrm{mL}$ (two-way ANOVA, $P=.0009$; Bonferroni test, $P<.05 ; M$. officinalis HLE $n=10$; ethanol $n=9$ ). M. officinalis HLE had no effect on contractile activity of ileum (Friedman's test: $P=.81[n=10])$, whereas ethanol decreased AUC at corresponding concentration of $50 \mathrm{mg} / \mathrm{mL}$ (Friedman's test: $P=.0002$ [ $n=10]$; Dunn's test: $P<.05$ vs. control). The difference between two treatments was not significant (two-way ANOVA, $P=.092 ;$ M. officinalis HLE $n=10$; ethanol $n=10$ ). 

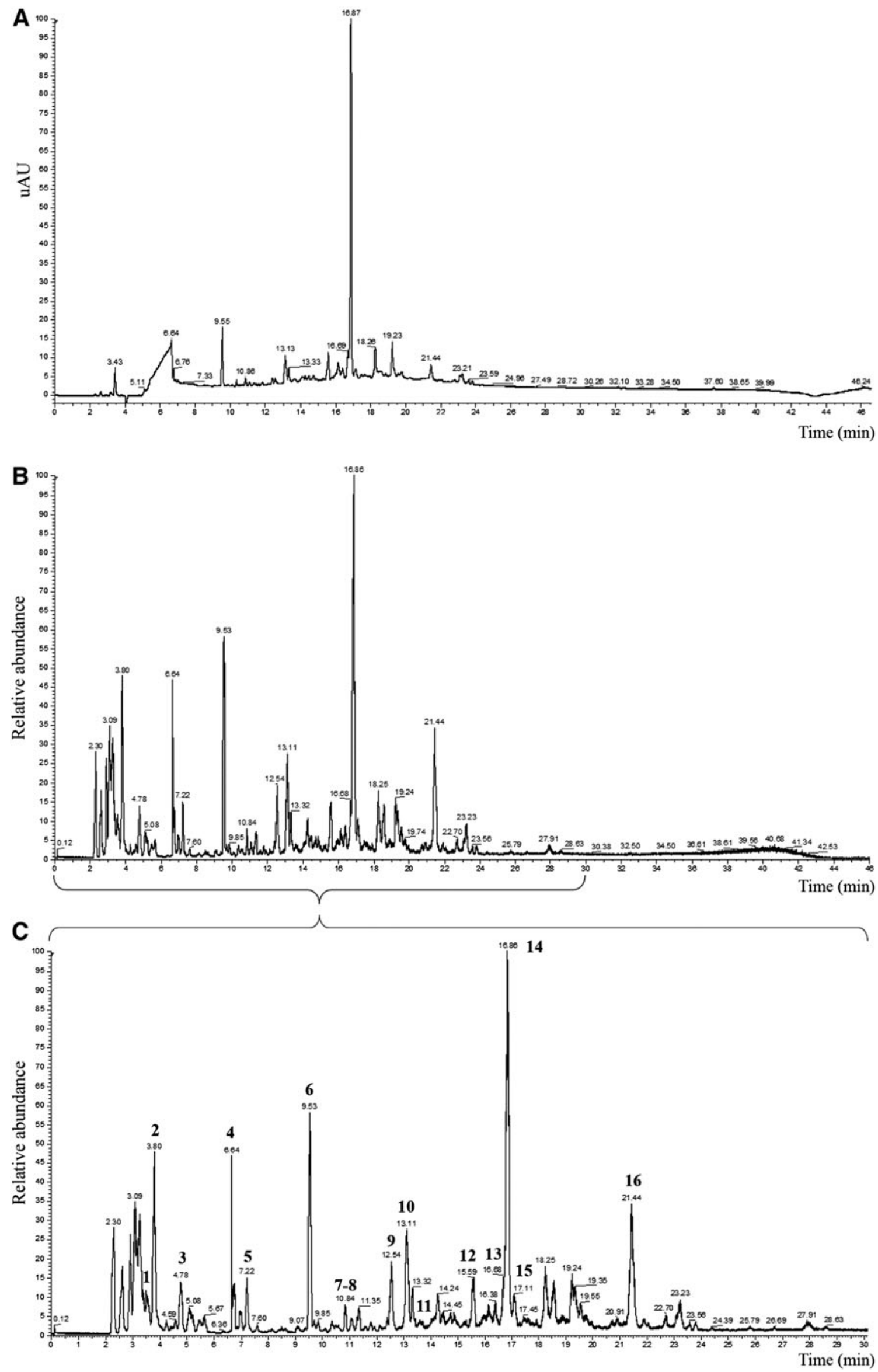

FIG. 1. UHPLC chromatograms of Melissa officinalis HLE. (A) UV at 190-400 nm; (B) mass spectrum in the negative ionization mode; (C) enlargement showing the 16 peaks identified. HLE, hydroethanolic leaf extract; UHPLC, ultra-high performance liquid chromatography; UV, ultraviolet. 
Table 1. Compounds Identified in Melissa officinalis Hydroethanolic Leaf Extract in the Negative Ionization Mode with Ultra-High Performance Liquid Chromatography MS and MS ${ }^{2}$

\begin{tabular}{|c|c|c|c|c|c|c|}
\hline Peak & $\begin{array}{l}\text { Retention } \\
\text { time (min) }\end{array}$ & $\begin{array}{c}\text { Molecular ion } \\
{[M-H]^{-}(\mathrm{m} / \mathrm{z})}\end{array}$ & Formula & $M S^{2}(m / z)$ & Compounds & Reference \\
\hline 1 & 3.59 & 149.0086 & $\mathrm{C}_{4} \mathrm{H}_{6} \mathrm{O}_{6}$ & $(149) / 87 / 72 / 59 / 103$ & Tartaric acid & Standard \\
\hline 2 & 3.80 & 191.0556 & $\mathrm{C}_{7} \mathrm{H}_{12} \mathrm{O}_{6}$ & $(191) / 85 / 127$ & Quinic acid & $\begin{array}{l}\text { MassBank of North } \\
\text { America Quinate }^{25}\end{array}$ \\
\hline 3 & 4.78 & 133.0137 & $\mathrm{C}_{4} \mathrm{H}_{6} \mathrm{O}_{5}$ & $115 / 71 /(133) / 89$ & Malic acid & 26 \\
\hline 4 & 6.64 & 191.0192 & $\mathrm{C}_{6} \mathrm{H}_{8} \mathrm{O}_{7}$ & $111 / 87 / 85 /(191)$ & Citric acid & $\begin{array}{l}\text { MassBank of North } \\
\text { America Citrate }^{27}\end{array}$ \\
\hline 5 & 7.22 & 117.0188 & $\mathrm{C}_{4} \mathrm{H}_{6} \mathrm{O}_{4}$ & 73/(117)/99 & Succinic acid & $\begin{array}{l}\text { MassBank of North } \\
\text { America Succinate }\end{array}$ \\
\hline 6 & 9.53 & 197.0450 & $\mathrm{C}_{9} \mathrm{H}_{10} \mathrm{O}_{5}$ & $72 / 135 / 123 / 179$ & Danshensu & 29 \\
\hline 7 & 10.84 & 311.0403 & $\mathrm{C}_{13} \mathrm{H}_{12} \mathrm{O}_{9}$ & $149 / 179 / 135 / 87$ & Caftaric acid & 30 \\
\hline 8 & 10.84 & 179.0345 & $\mathrm{C}_{9} \mathrm{H}_{8} \mathrm{O}_{4}$ & 135 & Caffeic acid (isomere) & Standard \\
\hline 9 & 12.54 & 137.0239 & $\mathrm{C}_{7} \mathrm{H}_{6} \mathrm{O}_{3}$ & (137) & Salicylic acid & 31 \\
\hline 10 & 13.11 & 179.0345 & $\mathrm{C}_{9} \mathrm{H}_{8} \mathrm{O}_{4}$ & 135 & Caffeic acid & Standard \\
\hline 11 & 13.71 & 537.1033 & $\mathrm{C}_{27} \mathrm{H}_{22} \mathrm{O}_{12}$ & 295/179/135/121/(493) & Lithospermic acid A & 32 \\
\hline 12 & 15.59 & 473.0720 & $\mathrm{C}_{22} \mathrm{H}_{18} \mathrm{O}_{12}$ & $149 / 179 / 135(311 / 293)$ & Chicoric acid & 26 \\
\hline 13 & 16.68 & 461.0720 & $\mathrm{C}_{21} \mathrm{H}_{18} \mathrm{O}_{12}$ & 285 & $\begin{array}{l}\text { Luteolin } 3^{\prime}-\mathrm{O}-\beta \text { - } \\
\text { D-glucuronide }\end{array}$ & $\begin{array}{l}\text { MassBank of North } \\
\text { America Luteolin-7-O- } \\
\text { glucoside }^{33}\end{array}$ \\
\hline 14 & 16.86 & 359.0767 & $\mathrm{C}_{18} \mathrm{H}_{16} \mathrm{O}_{8}$ & $161 / 197 / 179 / 135$ & Rosmarinic acid & Standard \\
\hline 15 & 17.11 & 537.1033 & $\mathrm{C}_{27} \mathrm{H}_{22} \mathrm{O}_{12}$ & $161 / 135 / 359 / 179 / 197$ & $\begin{array}{l}3^{\prime}-\mathrm{O}-\left(8^{\prime \prime}-\mathrm{Z} \text {-caffeoyl }\right) \\
\text { rosmarinic acid }\end{array}$ & 34 \\
\hline 16 & 21.44 & 207.0663 & $\mathrm{C}_{11} \mathrm{H}_{12} \mathrm{O}_{4}$ & $(207) / 135 / 179 / 161 / 134 / 133$ & Ethyl caffeate & 35 \\
\hline
\end{tabular}

MS, mass spectrometry; $\mathrm{MS}^{2}$, tandem mass spectrometry.

In precontracted conditions (Table 2 and Fig. 4), frequency of spontaneous phasic contractions of ileum was significantly decreased with $M$. officinalis HLE at $50 \mathrm{mg} / \mathrm{mL}$ (corresponding to $3.87 \mathrm{mg} / \mathrm{mL}$ of dry material; Friedman's test: $P<.0001[n=9$ ]; Dunn's test: $-91.9 \% \pm 8.1 \%, P<.05$ vs. control [i.e., before treatment]) and ethanol at corresponding concentration of $25 \mathrm{mg} / \mathrm{mL}$ (Friedman's test: $P=.0008$ $[n=10]$; Dunn's test: $P<.05)$. The difference between the two treatments was statistically significant at $50 \mathrm{mg} / \mathrm{mL}$ (two-way ANOVA, $P<.0001$; Bonferroni test, $P<.05$; M. officinalis HLE $n=9$; ethanol $n=10$ ). As for contractile activity, both $M$. officinalis HLE and ethanol induced a significant decrease in the AUC at 10,25 , and $50 \mathrm{mg} / \mathrm{mL}$ (for HLE, doses correspond, respectively, to 0.77, 1.9, and $3.87 \mathrm{mg} / \mathrm{mL}$ of dry material; Friedman's test: $P<.0001$, Dunn's test: $P<.05$ vs. control for both $M$. officinalis HLE $[n=9]$ and ethanol $[n=10] ;-36.2 \% \pm 7.8 \%,-78.8 \% \pm 12.0 \%$, and $-99.7 \% \pm 15.6 \%$, respectively for $M$. officinalis HLE). The decrease in AUC observed with M. officinalis HLE was not significantly different from that with ethanol (two-way ANOVA, $P=.11 ;$ M. officinalis HLE $n=9$; ethanol $n=10$ ).

Proximal colon. Although M. officinalis HLE significantly increased colon contractile activity in basal conditions (Table 2; Friedman's test: $P<.045$ vs. control [i.e., previous treatment] $[n=9]$ ), ethanol significantly decreased the AUC at corresponding concentrations of 25 and $50 \mathrm{mg} / \mathrm{mL}$ (Friedman's test: $P<.0001[n=10]$; Dunn's test: $P<.05)$, the difference between the two treatments was not significant (two-way ANOVA, $P=.25 ; M$. officinalis HLE $n=9$; ethanol $n=10$; data not shown).

In precontracted conditions, $M$. officinalis HLE had no effect on the contractile activity of proximal colon (Friedman's test: $P=.25[n=9])$, whereas ethanol significantly decreased 
Table 2. Summary of the Effects of Melissa officinalis Hydroethanolic Leaf Extract on the Different Parts of the Gastrointestinal Tract

\begin{tabular}{|c|c|c|c|c|c|}
\hline \multirow[b]{2}{*}{ GI part } & \multirow[b]{2}{*}{ Treatment } & \multicolumn{2}{|c|}{$\begin{array}{c}\text { Basal effects } \\
\text { (basal conditions) }\end{array}$} & \multicolumn{2}{|c|}{$\begin{array}{c}\text { Spasmolytic effects } \\
\text { (precontracted conditions) }\end{array}$} \\
\hline & & $\begin{array}{c}\text { Frequency of } \\
\text { spontaneous phasic } \\
\text { contractions }\end{array}$ & $\begin{array}{l}\text { Contractile activity } \\
(A U C)\end{array}$ & $\begin{array}{c}\text { Frequency of } \\
\text { spontaneous phasic } \\
\text { contractions }\end{array}$ & $\begin{array}{c}\text { Contractile activity } \\
(A U C)\end{array}$ \\
\hline \multirow[t]{3}{*}{ Antrum } & M. officinalis $\mathrm{HLE}(\mathrm{mg} / \mathrm{mL})$ & $\downarrow$ at 25 and 50 & NS & NS & NS \\
\hline & Ethanol (equiv. mg/mL) & $\downarrow$ at 25 and 50 & $\downarrow$ at 5 and 10 & $\downarrow$ at 50 & $\downarrow$ at 25 and 50 \\
\hline & Comparison $M$. officinalis/ethanol & NS & NS & NS & NS \\
\hline \multirow[t]{3}{*}{ Jejunum } & M. officinalis HLE (mg/mL) & $\downarrow$ at 25 and 50 & $\downarrow$ at 10,25 and 50 & $\downarrow$ at 25 and 50 & $\downarrow$ at 10,25 and 50 \\
\hline & Ethanol (equiv. mg/mL) & NS & NS & NS & $\downarrow$ at 10,25 and 50 \\
\hline & Comparison $M$. officinalis/ethanol & $\downarrow$ at 25 and 50 & $\downarrow$ at 10,25 and 50 & $\downarrow$ at 50 & $\downarrow$ at 10,25 and 50 \\
\hline \multirow[t]{3}{*}{ Ileum } & M. officinalis HLE $(\mathrm{mg} / \mathrm{mL})$ & $\downarrow$ at 50 & NS & $\downarrow$ at 50 & $\downarrow$ at 10,25 and 50 \\
\hline & Ethanol (equiv. mg/mL) & NS & $\downarrow$ at 50 & $\uparrow$ at 25 & $\downarrow$ at 10,25 and 50 \\
\hline & Comparison $M$. officinalis/ethanol & $\downarrow$ at 25 and 50 & NS & $\downarrow$ at 50 & NS \\
\hline \multirow{3}{*}{ Colon } & M. officinalis HLE (mg/mL) & - & $\uparrow$ & - & NS \\
\hline & Ethanol (equiv. mg/mL) & - & $\downarrow$ at 25 and 50 & - & $\downarrow$ at 25 and 50 \\
\hline & Comparison $M$. officinalis/ethanol & - & NS & - & NS \\
\hline
\end{tabular}

-, not tested; AUC, area under the curve; GI, gastrointestinal; HLE, hydroethanolic leaf extract; NS, not significant.

AUC at 25 and $50 \mathrm{mg} / \mathrm{mL}$ (Friedman's test: $P<.0001[n=10]$; Dunn's test: $P<.05)$. The difference between two treatments was not significant (two-way ANOVA, $P<.77 ; M$. officinalis HLE $n=9$; ethanol $n=10$ ).

\section{DISCUSSION}

Our results show that the HLE of M. officinalis tested has site- and dose-dependent effects on the contractile activity of the GI tract that do not depend on its vehicle (ethanol). In particular, M. officinalis HLE affected motility response in jejunum and ileum, whereas it had no effect on antrum and colon.

As for the small intestine, M. officinalis HLE inhibited AUC and contractile frequency at low concentrations for which ethanol had no effect. In addition, at higher concentration, the amplitude of effects was also significantly higher than that observed with ethanol (when it had an effect).

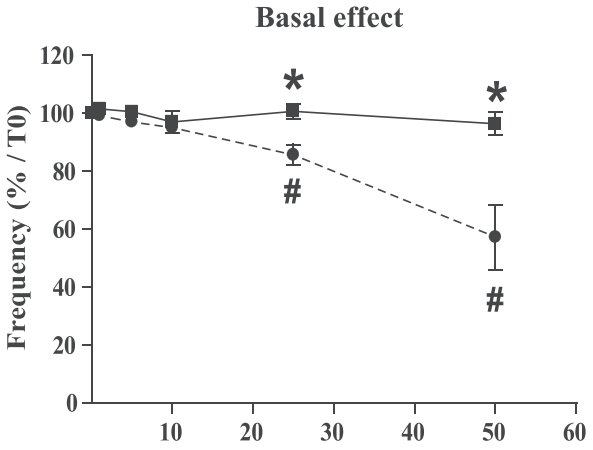

[M. officinalis HLE / Ethanol] $\mathrm{mg} / \mathrm{mL}$

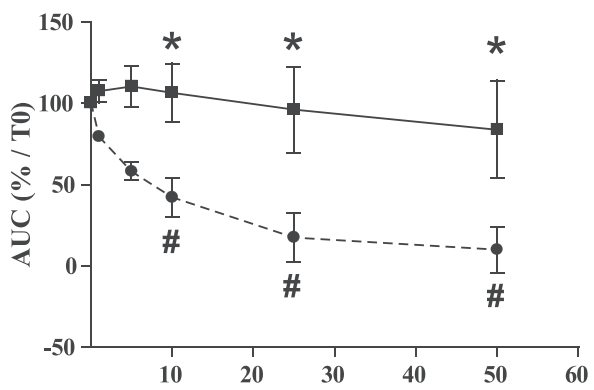

[M. officinalis HLE / Ethanol] $\mathrm{mg} / \mathrm{mL}$
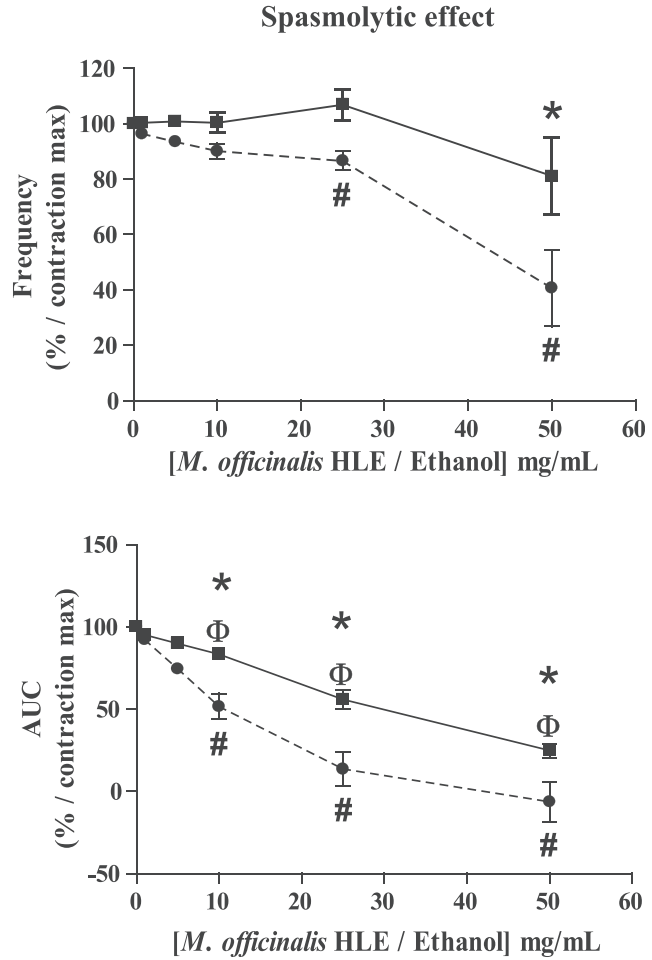

FIG. 2. Effects of M. officinalis HLE on the jejunum. Friedman's test followed by Dunn's test were used to analyze the dose-response effect of M. officinalis HLE or ethanol and values that are significantly different from control (i.e., previous treatment) are indicated respectively by \# and $\Phi$. Treatment effects were compared using two-way ANOVA for repeated measures followed by Bonferroni post hoc test and values that are significantly different are indicated by *. ANOVA, analysis of variance; AUC, area under the curve. 
A Basal effects

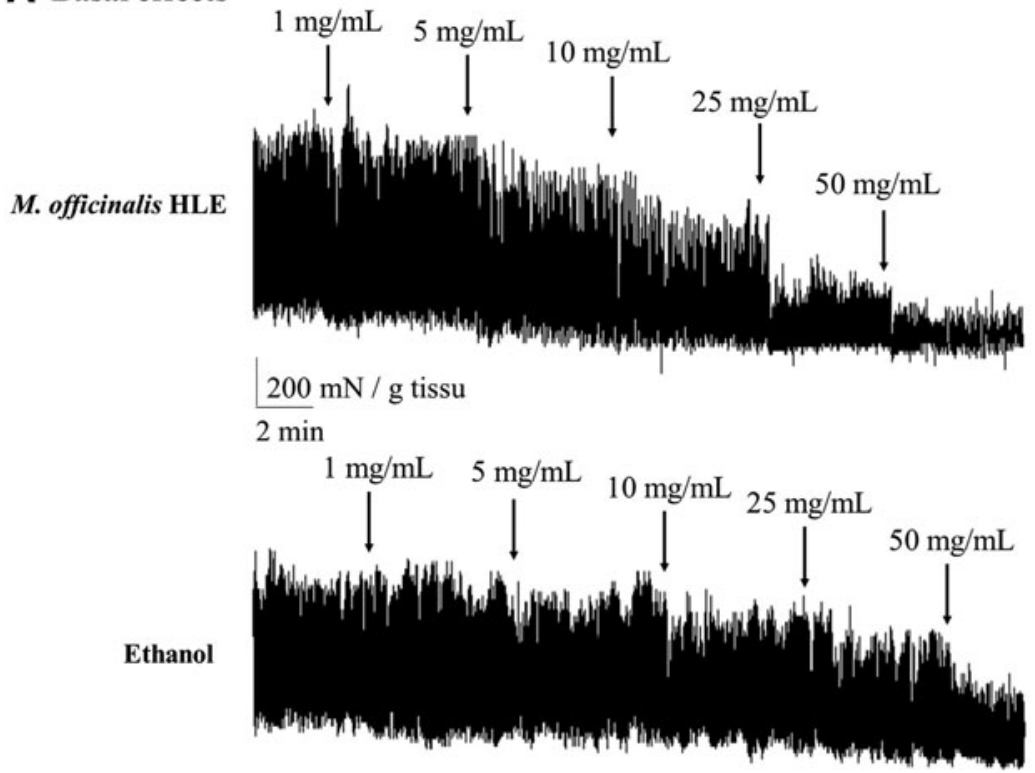

\section{B Spasmolytic effects}

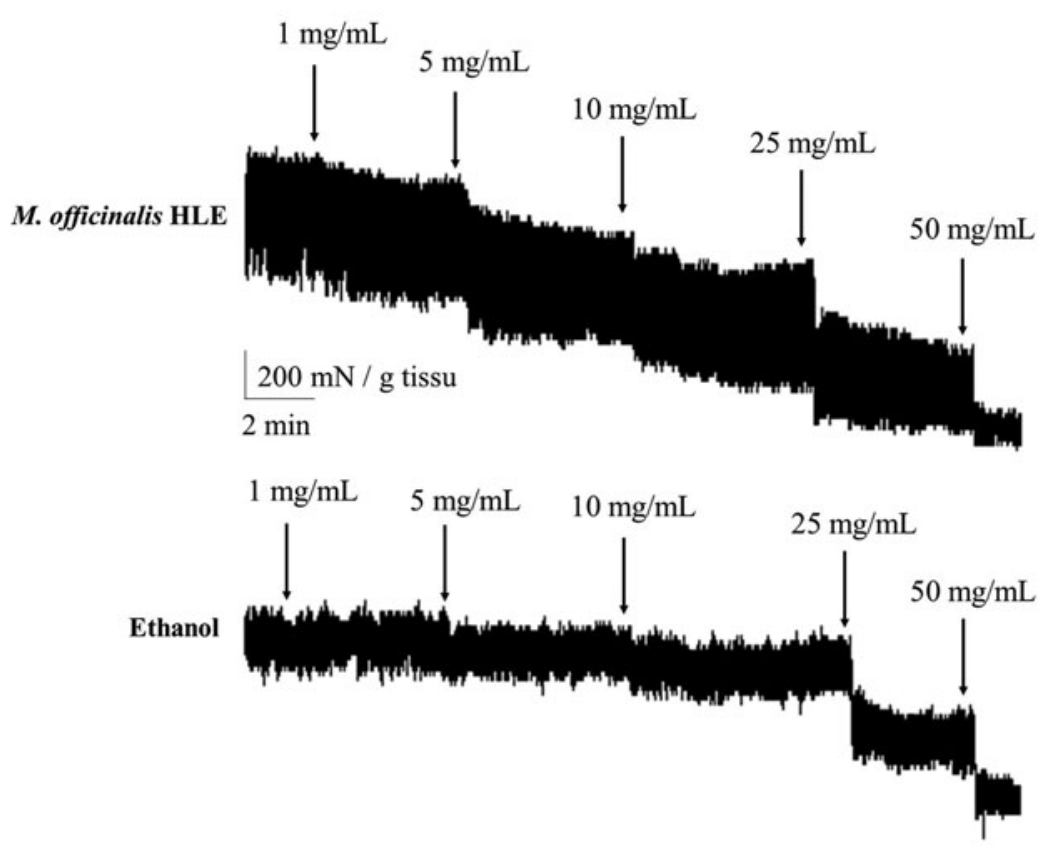

FIG. 3. Typical recording of $M$. officinalis HLE and ethanol dose-response inhibition of contraction of isolated jejunum longitudinal muscle strip from mice under basal conditions (A) and precontracted conditions (B).
Whether these changes observed ex vivo impact intestinal transit remains to be assessed in vivo. However, this decrease in contractile activity observed both under basal condition and after precontraction could lead to slower intestinal transit. Conversely, spasmolytic activity could contribute to reduce intestinal sensitivity. Consistent with our findings, inhibitory effects of $M$. officinalis on ileum have been reported in several studies. ${ }^{6,711}$ In brief, an ethanol extract of $M$. officinalis folium inhibited histamine-induced contractions of guinea pig ileum, whereas an aqueous extract was inactive. ${ }^{11}$ Interestingly, a hydroethanolic extract (30\% ethanol dose unknown) also decreased histamine-induced contractions and amplitude of spontaneous contractions in the guinea pig ileum in comparison with solvent control. ${ }^{7}$ However, this extract had no effect on amplitude and frequency of slow waves in circular smooth muscle of mouse small intestine, suggesting other mechanisms of action underlying functional effects of the extract (such as altering intracellular calcium homeostasis). ${ }^{10}$ In addition, no antispasmodic activity was observed for a hydroethanolic extract (30\% ethanol; 2.5 and $10 \mathrm{~mL} / \mathrm{L})$ in the guinea pig ileum. ${ }^{6}$ Finally, our study also extended spasmolytic activity of $M$. officinalis HLE to the jejunum that seems to be more sensitive to the extract both under basal and precontracted conditions. 

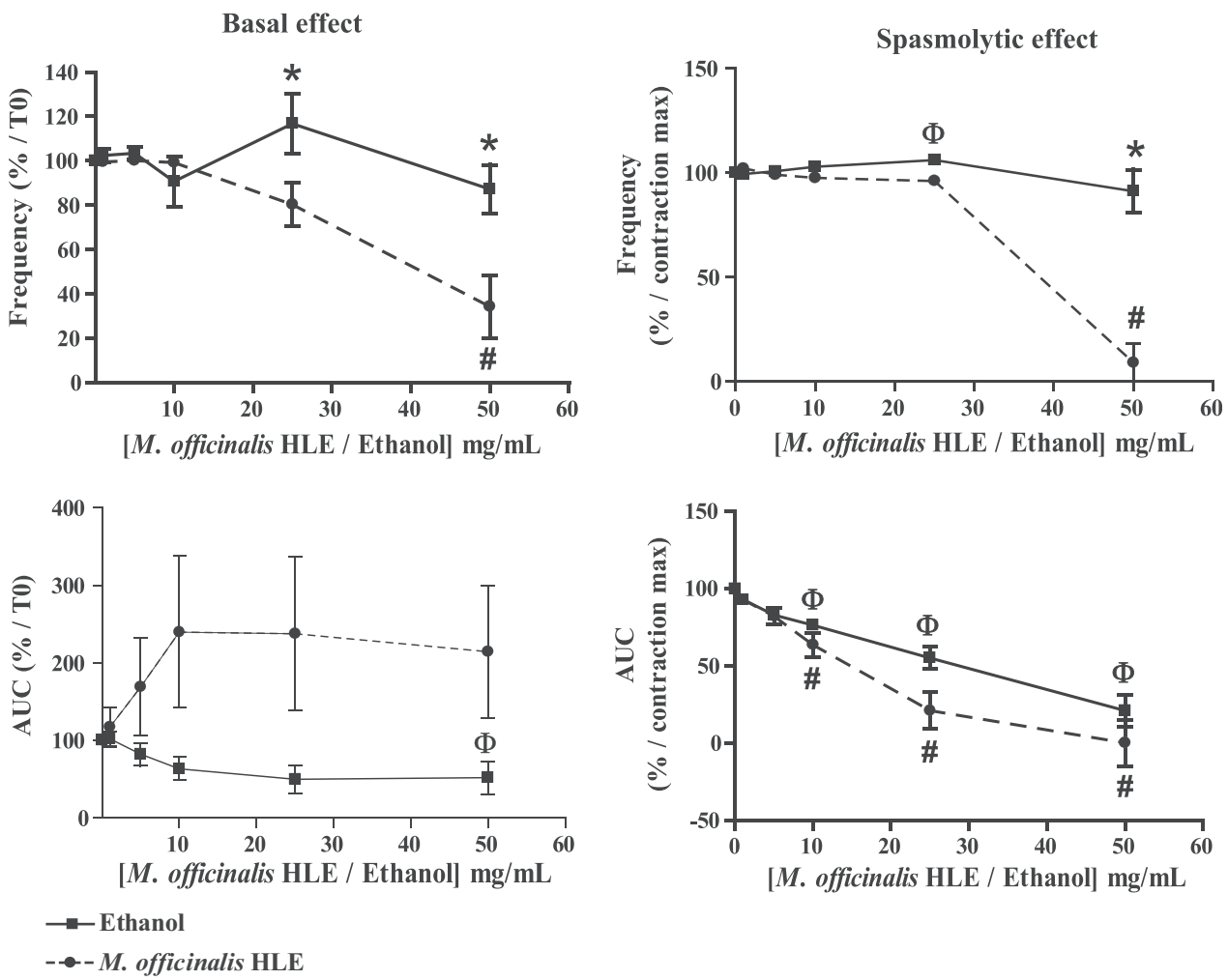

FIG. 4. Effects of $M$. officinalis HLE on the ileum. Friedman's test followed by Dunn's test were used to analyze the dose-response effect of $M$. officinalis HLE or ethanol and values that are significantly different from control (i.e., previous treatment) are indicated respectively by $\#$ and $\Phi$. Treatment effects were compared by using twoway ANOVA for repeated measures followed by Bonferroni post hoc test and values that are significantly different are indicated by $*$.
Of interest, $M$. officinalis HLE had no effects on antrum and colon contractile activity but seemed to antagonize the effects of ethanol. As several studies showed that gastric emptying was slowed by ethanol (e.g., Jian et al. ${ }^{12}$ ), our results suggest that $M$. officinalis could prevent ethanolinduced slowing of gastric emptying. In contrast to our findings, a $M$. officinalis extract used as an ethanol-free lyophilisate induced a small but significant contractile response in the antrum. ${ }^{8}$ In our study, M. officinalis HLE had no significant effects on proximal colon motility; these results are similar to those of Sibaev et al. who reported that an ethanolic extract of lemon balm had no effect on amplitude and frequency of slow waves in the colon. ${ }^{9}$ The underlying mechanisms of the organ-specific effects of $M$. officinalis reported in our study remains currently unknown. It could however reflect differences in properties of smooth muscle cells and/or interstitial cells of Cajal between different gut segments. These differences are probably not because of region-specific differences in the neurochemical phenotype of the enteric nervous system as previous studies have shown that SWT 5 (that contains among others $M$. officinalis) effects were not modified by synaptic transmission blockers. $^{13}$

Main compounds found in M. officinalis HLE were rosmarinic acid, and other phenolic compounds, as previously reported in literature..$^{3,14,15}$ Our phytochemical analysis also revealed hydroxyl cinnamic acids such as caffeic acid and derivatives, and of several compounds containing carboxylic acid function including quinic, citric, and salicylic acids. Luteolin $3^{\prime}$-O- $\beta$-D-glucuronide was also found; this substance was previously reported as the major flavone present in M. officinalis. ${ }^{14,15}$ Which individual component or group of components of $M$. officinalis influences GI activity and is responsible for which specific effect will have to be answered in future investigations. However, effects of $M$. officinalis are mainly attributed to phenolic compounds and its essential oil. ${ }^{3}$ Studies performed with the essential oil of M. officinalis showed a myorelaxant effect on different parts of the small intestine in various species. ${ }^{16-19}$ However, as shown in our phytochemical analysis our extract does not contain essential oil (no terpenes were detected). Therefore, effects observed cannot be attributed to essential oil, but are likely because of rosmarinic acid and/or other phenolic compounds. An aqueous extract of $M$. officinalis was reported to have a vasorelaxant effect on the rat isolated thoracic aorta. ${ }^{20}$ Rosmarinic acid was the most abundant compound in this extract, and the authors confirmed that the compound exerted a vasorelaxant effect. Rosmarinic acid was also found to have spasmolytic effects on rat uterus. ${ }^{21}$ However, rosmarinic acid (from thyme) had no antispasmodic activity in a preconstricted rat smooth muscle trachea model; the effect observed was attributed to luteolin. ${ }^{22}$ Therefore, luteolin $3^{\prime}$-O- $\beta$-D-glucuronide present in our extract could be, at least partly, at the origin of observed effects.

Overall, the effects of $M$. officinalis HLE tested on gut motility are site and dose dependent. Whether the effects observed ex vivo have an impact on intestinal transit will have to be assessed in vivo. These effects could be because of an action of phenolic compounds but further experiments 
will have to confirm this hypothesis. Benefits of $M$. officinalis could be related to site-dependent spasmolytic actions, besides its previously described anti-inflammatory, antinociceptive, and prosecretory action. 3,23,24

\section{ACKNOWLEDGMENTS}

Part of the animal experiments was carried out within the small animal exploration facility Therassay (Nantes), which is supported by the GIS-IBiSA (Groupement d'Intérêt Scientifique-Infrastructure en Biologie Santé et Agronomie) program. The research did not receive any specific grant from funding agencies in the public, commercial, or not-for-profit sector.

\section{AUTHOR DISCLOSURE STATEMENT}

I.G. and C.B. are, respectively, research project manager and medical writer at PiLeJe Laboratoire. Valérie Bardot (PiLeJe Industrie), I.R. and P.C. were involved in the chromatographic analyses. P.A. and M.N. performed the animal experiments for PiLeJe Laboratoire.

\section{REFERENCES}

1. Kennedy DO, Wake G, Savelev S, et al:: Modulation of mood and cognitive performance following acute administration of single doses of Melissa officinalis (Lemon balm) with human CNS nicotinic and muscarinic receptor-binding properties. Neuropsychopharmacology 2003;28:1871-1881.

2. Savino F, Cresi F, Castagno E, Silvestro L, Oggero R: A randomized double-blind placebo-controlled trial of a standardized extract of Matricariae recutita, Foeniculum vulgare and Melissa officinalis (ColiMil) in the treatment of breastfed colicky infants. Phytother Res 2005;19:335-340.

3. Shakeri A, Sahebkar A, Javadi B: Melissa officinalis L. - A review of its traditional uses, phytochemistry and pharmacology. J Ethnopharmacol 2016;188:204-228.

4. European Medicine Agency: Community Herbal Monograph on Melissa officinalis L., Folium. 2013. www.ema.europa.eu/docs/en_ GB/document_library/Herbal_-_Community_herbal_monograph/ 2013/08/WC500147189.pdf (accessed July 3, 2018).

5. European Scientific Cooperative on Phytotherapy: ESCOP Monograph on Melissae Folium. Exeter, England, 2013. Online series. www.escop.com.

6. Forster HB, Niklas H, Lutz S: Antispasmodic effects of some medicinal plants. Planta Med 1980;40:309-319.

7. Heinle H, Hagelauer D, Pascht U, Kelber O, Weiser D: Intestinal spasmolytic effects of STW 5 (Iberogast) and its components. Phytomedicine 2006;13 Suppl 5:75-79.

8. Schemann M, Michel K, Zeller F, Hohenester B, Rühl A: Region-specific effects of STW 5 (Iberogast) and its components in gastric fundus, corpus and antrum. Phytomedicine 2006;13 Suppl 5:90-99.

9. Sibaev A, Yuece B, Kelber O, et al.: STW 5 (Iberogast) and its individual herbal components modulate intestinal electrophysiology of mice. Phytomedicine 2006;13 Suppl 5:80-89.

10. Storr M, Sibaev A, Weiser D, et al.: Herbal extracts modulate the amplitude and frequency of slow waves in circular smooth muscle of mouse small intestine. Digestion 2004;70:257-264.
11. Itokawa $\mathrm{H}$, Mihashi $\mathrm{S}$, Watanabe $\mathrm{K}$, Natsumoto $\mathrm{H}$, Hamanaka $\mathrm{T}$ : Studies on the constituents of crude drugs having inhibitory activity against contraction of the ileum caused by histamine or barium chloride. I. Screening test for the activity of commercially available crude drugs and the related plant materials. Shoyakugaku Zasshi 1983;37:223-228.

12. Jian R, Cortot A, Ducrot F, Jobin G, Chayvialle JA, Modigliani $\mathrm{R}$ : Effect of ethanol ingestion on postprandial gastric emptying and secretion, biliopancreatic secretions, and duodenal absorption in man. Dig Dis Sci 1986;31:604-614.

13. Hohenester B, Rühl A, Kelber O, Schemann M: The herbal preparation STW5 (lberogast) has potent and region-specific effects on gastric motility. Neurogastroenterol Motil 2004;16:765773.

14. Barros L, Dueñas M, Dias MI, Sousa MJ, Santos-Buelga C, Ferreira ICFR: Phenolic profiles of cultivated, in vitro cultured and commercial samples of Melissa officinalis L. infusions. Food Chem 2013;136:1-8.

15. Heitz A, Carnat A, Fraisse D, Carnat A-P, Lamaison J-L: Luteolin 3 -glucuronide, the major flavonoid from Melissa officinalis subsp. officinalis. Fitoterapia 2000;71:201-202.

16. Debelmas AM, Rochat J: Pharmacological study of essential oils. Antispasmodic activity studied on about fifty different samples. Plantes Médicinales et Phytotherapie 1967;1:23-27.

17. Reiter M, Brandt W: Relaxant effects on tracheal and ileal smooth muscles of the guinea pig. Arzneimittelforschung 1985; 35:408-414.

18. Sadraei H, Ghannadi A, Malekshahi K: Relaxant effect of essential oil of Melissa officinalis and citral on rat ileum contractions. Fitoterapia 2003;74:445-452.

19. Wagner H, Sprinkmeyer L: Über die pharmakologische Wirkung von Melissengeist. Deutsche Apotheker Zeitung 1973;113:11591166.

20. Ersoy S, Orhan I, Turan NN, Sahan G, Ark M, Tosun F: Endothelium-dependent induction of vasorelaxation by Melissa officinalis L. ssp. officinalis in rat isolated thoracic aorta. Phytomedicine 2008;15:1087-1092.

21. Perez-Hernandez N, Ponce-Monter H, Medina JA, JosephNathan P: Spasmolytic effect of constituents from Lepechinia caulescens on rat uterus. J Ethnopharmacol 2008;115:30-35.

22. Engelbertz J, Lechtenberg M, Studt L, Hensel A, Verspohl EJ: Bioassay-guided fractionation of a thymol-deprived hydrophilic thyme extract and its antispasmodic effect. J Ethnopharmacol 2012;141:848-853.

23. Allam S, Krueger D, Demir IE, Ceyhan G, Zeller F, Schemann M: Extracts from peppermint leaves, lemon balm leaves and in particular angelica roots mimic the pro-secretory action of the herbal preparation STW 5 in the human intestine. Phytomedicine 2015;22:1063-1070.

24. Amoah SKS, Sandjo LP, Kratz JM, Biavatti MW: Rosmarinic acid-Pharmaceutical and clinical aspects. Planta Med 2016;82: 388-406.

25. MassBank of North America: Quinate. http://mona.fiehnlab .ucdavis.edu/spectra/display/KO001747 (accessed February 11, 2019).

26. Mascherpa D, Carazzone C, Marrubini G, Gazzani G, Papetti A: Identification of phenolic constituents in Cichorium endivia var. crispum and var. latifolium salads by high-performance liquid chromatography with diode array detection and electrospray 
ioniziation tandem mass spectrometry. J Agric Food Chem 2012; 60:12142-12150.

27. MassBank of North America: Citrate. http://mona.fiehnlab .ucdavis.edu/spectra/display/FiehnHILIC001123 (accessed February 11,2019 ).

28. MassBank of North America: Succinate. http://mona.fiehnlab .ucdavis.edu/spectra/display/PT203440 (accessed February 11, 2019).

29. Wang X, Li W, Ma X, et al:: Identification of a major metabolite of danshensu in rat urine and simultaneous determination of danshensu and its metabolite in plasma: Application to a pharmacokinetic study in rats. Drug Test Anal 2015;7:727-736.

30. Chen H-J, Inbaraj BS, Chen B-H: Determination of phenolic acids and flavonoids in Taraxacum formosanum Kitam by liquid chromatography-tandem mass spectrometry coupled with a postcolumn derivatization technique. Int J Mol Sci 2012;13:260-285.

31. Sun J, Liang F, Bin Y, Li P, Duan C: Screening non-colored phenolics in red wines using liquid chromatography/ultraviolet and mass spectrometry/mass spectrometry libraries. Molecules 2007;12:679-693.

32. Wang S, Liu L, Wang L, Hu Y, Zhang W, Liu R: Structural characterization and identification of major constituents in Jitai tablets by high-performance liquid chromatography/diode-array detection coupled with electrospray ionization tandem mass spectrometry. Molecules 2012;17:10470-10493.

33. MassBank of North America: Luteolin-7-O-glucoside. http:// mona.fiehnlab.ucdavis.edu/spectra/display/PM011105 (accessed February 11, 2019).

34. Pereira OR, Peres AM, Silva AM, Domingues MR, Cardoso SM: Simultaneous characterization and quantification of phenolic compounds in Thymus x citriodorus using a validated HPLC-UV and ESI-MS combined method. Food Res Int 2013;54:17731780.

35. Lambert M, Meudec E, Verbaere A, et al:: A high-throughput UHPLC-QqQ-MS method for polyphenol profiling in rosé wines. Molecules 2015;20:7890-7914. 